\title{
O COMPROMETIMENTO ORGANIZACIONAL, A QUALIDADE TÉCNICA E O TEMPO NA EQUIPE COMO ANTECEDENTES DA CENTRALIDADE DOS ATLETAS NAS REDES DE CONFIANÇA DE EQUIPES ESPORTIVAS
}

\author{
ORGANIZATIONAL COMMITMENT, TECHNICAL \\ QUALITY AND TIME IN THE TEAM AS ANTECEDENTS TO \\ ATHLETE'S CENTRALITY IN SPORTS TEAM TRUST \\ NETWORKS
}

\section{COMPROMISO CON LA ORGANIZACIÓN, CALIDAD TÉCNICA Y TIEMPO EN EQUIPO COMO ANTECEDENTES DE LA CENTRALIDAD DE ATLETAS EN LAS REDES DE CONFIANZA DE EQUIPOS DEPORTIVOS}

\author{
Ronan Kayano Genoino \\ Mestre em Administração (Gestão do Esporte) pela \\ Universidade Nove de Julho (UNINOVE), Brasil \\ ronangenoino13@gmail.com \\ João Paulo Lara Siqueira \\ Universidade Nove de Julho (UNINOVE), Brasil / \\ Doutor em Administração \\ joaopaulolaradesiqueira@gmail.com
}

\author{
Contextus \\ ISSNe 2178-9258 \\ Organização: Comitê Científico Interinstitucional \\ Editor Científico: Carlos Adriano Santos Gomes \\ Avaliação: double blind review pelo SEER/OJS \\ Edição de texto e de layout: Carlos Daniel Andrade \\ Recebido em 16/01/2017 \\ Aceito em 23/10/2017 \\ $2^{a}$ versão aceita em 08/11/2017
}

\section{RESUMO}

$\mathrm{O}$ estudo investigou o que leva um ator a ter maior centralidade nas redes de confiança de equipes esportivas, verificando a relação da centralidade com o comprometimento organizacional, a qualidade técnica e o tempo na equipe. A pesquisa teve como base as redes de confiança, um tipo de rede informal formada pelas relações de confiança interpessoal entre os membros de uma organização. Com caráter qualitativo e exploratório-descritivo, analisou atletas de duas equipes esportivas. Foram coletados dados por meio de questionários respondidos pelos atletas, além de entrevistas semiestruturadas com os treinadores das equipes. Os resultados indicaram a existência de uma relação positiva entre os construtos, sendo a principal contribuição o paralelo que pode ser feito com o campo gerencial, em que profissionais mais comprometidos, qualificados e com mais tempo dentro das organizações podem gozar de maior confiança dentro do ambiente corporativo, resultando em um melhor desempenho organizacional.

Palavras-chave: Análise de redes sociais. Centralidade. Comprometimento organizacional. Redes de confiança. Redes sociais.

\begin{abstract}
The study investigated what leads an actor to have greater centrality within trust networks of sports teams by verifying the relationship between centrality and organizational commitment, technical quality and time of team membership. The research was based on the concept of trust networks, a type of informal network that is formed by interpersonal trust relationships among the members of an organization. It had a qualitative, exploratory-descriptive nature and analyzed athletes of two sports teams. Data were collected by means of both questionnaires answered by the athletes and semi-structured interviews with the team coaches. The results indicated the existence of a positive relationship between the constructs, the main contribution being the parallel that can be made with the managerial field, in which more committed, qualified and experienced professionals within the organizations can enjoy greater confidence within the environment, which amounts to better organizational performance.
\end{abstract}


Keywords: Social Network Analysis. Centrality. Organizational Commitment. Trust Networks. Social Networks.

\section{RESUMEN}

El estudio investigó lo que lleva un actor a tener mayor centralidad en las redes de confianza de equipos deportivos, verificando la relación de la centralidad con el compromiso con la organización, la calidad técnica y el tiempo en el equipo. La investigación se ha basado en las redes de confianza, un tipo de red informal que es formado por las relaciones de confianza interpersonal entre miembros de una organización. El estudio, de carácter cualitativo y exploratorio-descriptivo, analizó atletas de dos equipos deportivos. Los datos fueron recolectados por medio de cuestionarios contestados por los atletas y entrevistas semi-estructuradas con los entrenadores de los equipos. Los resultados indicaron la existencia de una relación positiva entre las construcciones, y la contribución principal es el paralelo que se puede hacer con el campo de gestión, donde profesionales más comprometidos, cualificados y con más tiempo dentro de las organizaciones pueden disfrutar de una mayor confianza en la empresa, lo que resulta en un mejor desempeño organizacional.

Palabras clave: Análisis de redes sociales. Centralidad. Compromiso con la organización. Redes de confianza. Redes sociales.

\section{INTRODUÇÃ̃O}

A frase "tudo está conectado a todo o resto" (LARSEN-FREEMAN, 2007, p. 37) ilustra bem a teoria das redes sociais. A sociedade moderna caracteriza-se pela existência de redes, com recursos e conhecimentos distribuídos entre diferentes atores, que podem ser indivíduos, grupos e/ou organizações, todos interdependentes (EDELENBOS; KLIJN, 2007). Pode-se entender uma rede como um grupo de atores autônomos, mas dependentes uns dos outros na medida em que agem coletivamente para produzir determinado objetivo comum, seja tangível ou intangível, que um ator não conseguiria produzir sozinho (ISETT et al., 2011).

Existe uma divisão entre dois tipos de redes no âmbito organizacional: as formais e as informais, sendo a segunda o foco do presente trabalho. Um tipo de rede informal, proposta por Krackhardt e Hanson (1993), é a rede de confiança, formada pelas relações entre indivíduos de determinado grupo que demonstra "quem confia em quem" (KRACKHARDT; HANSON, 1993, p. 106). A análise de uma rede desse tipo permite entender melhor as relações de confiança existentes em determinado ambiente, onde um ator com maior centralidade na rede será aquele que, em tese, goza de maior confiança dos demais (SARKER et al., 2011).

Enquanto conceito estudado no âmbito das redes sociais, a confiança está atrelada a diversos fatores positivos, como eficácia (ISETT et al., 2011; LECY; MERGEL; SCHMITZ, 2014), desempenho organizacional (CASIMIR; LEE; LOON, 2012), cooperação (CASIMIR; LEE; LOON, 2012; LI, 2005) e troca de 
conhecimentos (EDELENBOS; KLIJN, 2007; LI, 2005). Para Gould-Williams (2003), a confiança consiste em uma fonte de eficiência e eficácia organizacionais.

Em equipes, a confiança revela-se uma variável propícia à obtenção de objetivos em comum (LUSHER; KREMER; ROBINS, 2013). Na condição de mecanismo social que facilita a cooperação e coordenação dentro de uma rede, favorece um maior comprometimento (LI, 2005). Este, em contextos organizacionais, pode ser entendido como o vínculo emocional estabelecido entre um indivíduo e a organização (KIM; EISENBERGER; BAIK, 2016), também relacionado a melhores resultados organizacionais (CASIMIR; LEE; LOON, 2012).

A presente pesquisa voltou-se para a confiança em equipes esportivas, pois elas oferecem um contexto ideal para estudar interações e dinâmicas de grupo relacionadas ao desempenho, dados a natureza independente de sua formação e seus propósitos, que deixam claros os resultados a atingir $(\mathrm{MACH}$; DOLAN; TZAFRIR, 2010). Além disso, dentro de uma equipe esportiva, a confiança pode estar associada a determinadas características individuais, onde membros com mais experiência ou maior qualidade técnica podem gozar de mais confiança que os demais da equipe (LUSHER; KREMER; ROBINS, 2013). A qualidade técnica está relacionada às habilidades esportivas dos atletas, podendo ser definida como a capacidade de estes atingirem os resultados a que se propõem em determinada modalidade (BALBINO, 2008).

Nesse sentido, o objetivo do presente estudo foi investigar a centralidade dos atores na rede de confiança de equipes esportivas e identificar a possível relação com o comprometimento organizacional, com a qualidade técnica dos atletas e com o tempo na equipe. Assim, a questão de pesquisa que o presente artigo respondeu é: o comprometimento organizacional, a qualidade técnica dos atletas e o tempo na equipe têm relação direta com a centralidade dos atletas na rede de confiança?

A pesquisa caracteriza-se como qualitativa, com caráter exploratóriodescritivo, e foi feita com duas equipes esportivas, por meio da aplicação de questionários com os atletas $\mathrm{e}$ de entrevistas semiestruturadas com os treinadores. Os resultados apontaram 
empiricamente a existência de relação do comprometimento organizacional, do tempo na equipe e da qualidade técnica com a centralidade dos atletas nas redes de confiança. A principal contribuição do trabalho é o paralelo que pode ser feito com o campo gerencial, onde profissionais mais comprometidos, mais qualificados e com mais tempo dentro da empresa podem gozar de mais confiança no ambiente corporativo, resultando em um melhor desempenho organizacional.

Este trabalho está estruturado em seis seções. A próxima trata do referencial teórico, com uma revisão de literatura sobre redes sociais, redes de confiança, comprometimento organizacional e a relação entre confiança e comprometimento. A terceira seção contém os procedimentos metodológicos, com o delineamento da pesquisa, a amostra, bem como os procedimentos de coleta e análise dos dados. A seção seguinte traz os resultados coletados e sua análise. A quinta seção apresenta as considerações finais e contribuições gerenciais.

\section{REVISÃO DE LITERATURA}

\section{$2.1 \quad$ Redes sociais}

Uma das ideias mais difundidas nas ciências sociais é a de que as pessoas estão imersas em teias espessas de relações e interações sociais. A teoria das redes sociais busca explicar como a combinação de indivíduos autônomos resulta em sociedades duradouras e eficientes (BORGATTI et al., 2009). A metodologia mais utilizada nas pesquisas sobre redes é a Análise de Redes Sociais (ARS), preocupada com os aspectos individuais dos atores da rede, com as relações que se estabelecem entre eles, com o modo como são estruturadas tais relações e com o posicionamento dos atores dentro das redes (PRELL; HUBACEK; REED, 2009). A ARS, que representa com pontos ou nós os grupos e indivíduos e, com linhas ou laços, as relações sociais entre eles (SCOTT, 2011), identifica diversos atributos das redes, como por exemplo, a centralidade dos atores. Uma das vantagens de utilizar a ARS na análise de um time é a capacidade de estudá-lo como um sistema social, com foco não na autonomia dos indivíduos, mas nas relações entre eles em determinado contexto.

Seja como for, a ARS também possibilita investigar, de forma simultânea, os atributos individuais (LUSHER; ROBINS; KREMER, 2010). Dentro das redes, os indivíduos gozam de vantagens ou desvantagens de acordo 
com sua posição. A centralidade, que reflete o quanto determinado indivíduo está conectado aos demais, consiste no atributo associado, com maior frequência, a variáveis de desempenho, como poder, influência nas decisões e inovação (SPARROWE et al., 2001). É conceito fundamental para compreender redes informais, pois identifica os atores com papel mais importante nas dinâmicas e relações existentes na rede, ou seja, aqueles que ocupam posições estratégicas nas estruturas informais (MACAMBIRA; BASTOS, 2009).

Outra medida importante relacionada à centralidade é a relação entre centro e periferia: o centro, um grupo mais coeso, possui atores bastante ligados uns aos outros, enquanto a periferia é marcada por atores com poucas relações entre si ou mesmo nenhuma (SILVA et al., 2014; OLIVEIRA et al., 2007). A medida centro-periferia e a centralidade de rede, porém, são duas medidas distintas. De acordo com Borgatti e Everett (2000), a literatura aponta que todos atores dentro do centro de uma rede têm centralidade alta, porém o oposto não acontece, ou seja, nem todos atores com centralidade alta fazem parte do centro da rede. Em outros termos, a utilização do conceito de centro pode ser usada como indicativo de centralidade, mas o oposto não necessariamente se aplica.

\subsubsection{Redes de confiança}

As redes informais são aquelas formadas por meio das interações sociais entre os indivíduos, independentes da estrutura formal do grupo ou organização a que pertencem, podendo representar diversos tipos de interações sociais, como a troca de conselhos, informações, amizade e afeto (SODA; ZAHEER, 2012). As redes informais representam o que ocorre em uma organização em grau mais próximo da realidade do que organogramas ou representações de estruturas formais (GRANOVETTER, 1985).

Segundo Chou et al. (2006), o conceito de rede de confiança, capaz de ser considerado um dos principais do capital social, surgiu pela primeira vez em um trabalho de Krackhardt e Hanson (1993). Os autores, ambos pesquisadores de redes sociais, propuseram a existência de três tipos distintos de arquiteturas informais dentro das organizações: redes de conselhos, redes de comunicação e redes de confiança.

Existem duas principais 
definições para a confiança, a primeira sendo a crença de um determinado ator de que suas necessidades serão atendidas por meio das ações tomadas por outro (KIM; TRAIL, 2011). A segunda é a predisposição de uma parte em ficar vulnerável às ações de outra, com base na expectativa de que esta irá tomar decisões e ações importantes e benéficas para aquela (YAKOVLEVA; REILLY; WERKO, 2010).

A literatura mostra que a confiança está atrelada ao desempenho organizacional (GOULD-WILLIAMS, 2003), facilitando a cooperação voluntária entre atores independentes (CASIMIR; LEE; LOON, 2012). A confiança nos relacionamentos tem impacto direto sobre os processos organizacionais e sobre o desempenho, sendo um direcionador nas trocas, negociações e conflitos, resultando em relacionamentos mais tranquilos $\mathrm{e}$ menos conflituosos (ZAHEER; MCEVILY; PERRONE, 1998). Nesse sentido, "a confiança, a qual eu entendo como a convicção de que outros irão fazer a coisa certa mesmo diante de um claro balanço de incentivos contrários, emerge, se esse for o caso, no contexto de uma rede social" (GRANOVETTER, 2005, p. 34).
A centralidade de um ator em uma rede de confiança reflete o quanto ele goza da confiança dos demais membros de seu grupo, ou seja, a centralidade pode ser usada como indicador da confiança estabelecida entre os atores de uma rede: quanto maior a centralidade, maior o grau de confiança que um ator possui dentro da rede (SARKER et al., 2011).

\subsection{Comprometimento organizacional}

$\mathrm{O}$ comprometimento organizacional diz respeito aos sentimentos pessoais e ao vínculo psicológico estabelecido entre um indivíduo e a organização à qual pertence. Consiste em atributo relacionado aos comportamentos individuais de cada um, à identificação com as metas e valores da organização e ao desejo de nesta permanecer (JOO; PARK, 2010). Um estudo muito citado sobre $\quad 0 \quad$ comprometimento organizacional é o de Meyer e Allen (1991, p. 67), que propôs três dimensões para o comprometimento organizacional: afetivo, continuado e normativo.

\footnotetext{
O comprometimento afetivo se refere ao apego emocional, identificação e envolvimento de um funcionário com a organização. Funcionários com um forte comprometimento afetivo continuam
} 
trabalhando na organização porque eles querem. $\mathrm{O}$ comprometimento continuado se refere à consciência dos custos associados a deixar a organização. Funcionários cuja principal ligação com a organização é baseada no comprometimento continuado permanecem porque precisam. Finalmente, o comprometimento normativo reflete o sentimento de obrigação de continuar na organização. Funcionários com um alto nível de comprometimento normativo sentem que tem um dever de permanecer na organização.

Existem muitos estudos que relacionam o comprometimento organizacional a melhores resultados e comportamentos organizacionais, como desempenho, produtividade, satisfação pessoal e confiança (DHAR, 2015). O comprometimento organizacional inclusive é um índice frequentemente utilizado como sinal de eficácia em um time (CHOU et al., 2006).

No presente estudo, o comprometimento organizacional será abordado por meio da definição de Meyer e Allen (1991), com foco na dimensão afetiva, por esta ser aquela relacionada ao apego emocional, à identificação e ao envolvimento de um ator com sua organização e por ser a dimensão mais estabelecida e utilizada dentro da literatura sobre o tema (BOZIONELOS, 2008).

\subsection{Relação entre a confiança e o comprometimento organizacional}

A literatura aponta que o comprometimento organizacional e a confiança são construtos interligados (UGBORO, 2003), estando ambos os processos relacionados a um melhor desempenho e à dedicação de indivíduos com suas organizações (ZEFFANE; TIPU; RYAN, 2011). Segundo Rampersad, Quester e Troshani (2010), a literatura apresenta resultados contraditórios sobre a relação entre a confiança e o comprometimento: ora o comprometimento leva à confiança, ora é o inverso. A existência de estudos em ambos os sentidos indica uma forte relação entre os construtos. Ainda segundo os mesmos autores, tal vínculo, em redes de inovação, tem caráter positivo.

Yilmaz (2008) coloca que a confiança de um indivíduo em uma organização aumenta o seu comprometimento com ela. Para ele, o comprometimento surge do sentimento de confiança. Se uma pessoa acredita na integridade de uma organização, essa crença exerce impacto direto no seu comprometimento. Por meio da interação com a organização e suas dinâmicas, as pessoas começam a 
coletar as informações sobre ela, e o sentimento de confiança emerge como resultado das experiências prévias e dessas informações coletadas. GouldWilliams (2003) também indica a existência de relação entre a confiança e o comprometimento, colocando que a falta de confiança dentro de uma organização pode levar a diversos resultados negativos, como pouca motivação e um menor comprometimento organizacional.

Os comportamentos humanos, como a confiança e o comprometimento organizacional, estão relacionados às relações sociais que ocorrem entre diferentes indivíduos nos mais diversos contextos sociais. Nas palavras de Granovetter (1985, p. 487):

Os atores não se comportam nem tomam decisões como átomos fora de um contexto social, e nem adotam de forma servil um roteiro escrito para eles pela intersecção específica de categoriais sociais que eles porventura ocupem. Em vez disso, suas tentativas de realizar ações com propósito estão imersas em sistemas concretos e contínuos de relações sociais.

O presente estudo abordará a relação entre o comprometimento e a confiança colocando o primeiro como um antecedente do segundo. Apesar de a literatura apresentar resultados em ambos os sentidos, como o intuito deste trabalho é verificar o que leva a uma maior confiança, o comprometimento será colocado como variável independente e a centralidade de confiança como variável dependente.

\subsection{Equipes de alta performance}

\section{Conforme Katzenbach e Smith} (2001), ficou acentuada, desde a mudança da era industrial para a era do conhecimento, a importância das equipes de trabalho nas organizações, sendo isso um dos principais diferenciais competitivos no mundo corporativo. Para os autores, é fundamental desenvolver uma cultura organizacional que coloque as equipes como o principal ativo das empresas, estimulando a disseminação de ideias, a troca de conhecimentos e o trabalho em grupo.

Nesse sentido, destacam-se as equipes de alta performance, que podem ser entendidas como:

aquelas compostas de membros cujas habilidades, atitudes e competências lhes permitem atingir as metas da equipe. Em equipes de alto desempenho, os membros definem as metas, tomam decisões, comunicam-se, administram os conflitos e solucionam problemas em uma atmosfera de incentivo e confiança para atingir seus próprios objetivos. Além disso, os membros desta equipe estão cientes de suas próprias forças e fraquezas e tem a capacidade de mudar quando necessário para melhorar $\mathrm{O}$ desempenho do grupo (DYER; DYER; DYER, 2011, p. 23). 
As equipes de alta performance necessitam de membros que saibam trabalhar em equipe, combinando e potencializando suas habilidades e competências na busca de objetivos em comum. Ou seja, o bom desempenho das equipes requer que cada membro cumpra com suas responsabilidades e coloque os objetivos da equipe sempre em primeiro plano, em detrimento dos objetivos e desejos pessoais de cada um (CASTKA et al., 2001).

\section{PROCEDIMENTO METODOLÓGICO}

\subsection{Delineamento da pesquisa}

A pesquisa teve caráter qualitativo e exploratório-descritivo. Foi qualitativa devido ao fato de não se utilizar de instrumentos e técnicas estatísticas para a análise dos dados. E, como qualquer pesquisa exploratória, teve como objetivo estimular a compreensão e proporcionar uma maior familiaridade com o problema de pesquisa, por meio do aprimoramento de ideias ou da descoberta de intuições (GIL, 2002). Quanto ao caráter descritivo, manifestou-se no propósito da pesquisa em descrever as características de determinada população ou fenômeno, bem como na utilização de técnicas padronizadas para a coleta de dados, como a utilização de questionários (GIL, 2002).

\subsection{Amostra da pesquisa}

A pesquisa foi realizada em novembro de 2016 com atletas do Centro Olímpico de Treinamento e Pesquisa (COTP), um centro esportivo público da Secretaria Municipal de Esportes, Lazer e Recreação (SEME) da cidade de São Paulo, voltado ao treinamento de esporte de alto rendimento. O COTP é o único equipamento da SEME com esse fim, enquanto, nos demais centros esportivos da Prefeitura de São Paulo, o foco é o esporte de participação, sem preocupação com o desempenho esportivo (PREFEITURA DE SÃO PAULO, 2016).

Foram selecionadas duas equipes do COTP, ambas da categoria Sub-17, para atletas com 17 anos ou menos, das modalidades futebol e voleibol. A equipe de futebol era do sexo feminino, enquanto a de voleibol, do masculino. As equipes esportivas oferecem um contexto ideal para o estudo de interações e dinâmicas de grupos relacionadas ao desempenho, por terem 
uma formação independente e propósitos claros de atingir resultados (MACH; DOLAN; TZAFRIR, 2010).

\subsection{Procedimentos de coleta dos dados}

Os dados para a pesquisa, sempre considerados primários, foram coletados por meio da aplicação de questionários e de entrevistas semiestruturadas.

A primeira ferramenta foi aplicada pelo próprio pesquisador com uma equipe de cada vez. Antes da pesquisa, seu intuito foi explicado aos atletas, e garantiram-se o anonimato e a não divulgação de dados pessoais. Também foi ressaltada a importância de responder aos questionários da forma mais verdadeira possível, de forma a não prejudicar os resultados. Os atletas também foram alocados em lugares distantes uns dos outros e orientados a não olhar as respostas dos colegas. Os questionários foram aplicados a todos os atletas das duas equipes pesquisadas, com o intuito de obter os resultados da rede completa, com um total de 37 atletas, sendo 18 do futebol feminino e 19 do voleibol feminino. Foram levantados dados pessoais e demográficos, além de outros, sociométricos, destinados a mensurar a rede de confiança, o comprometimento organizacional, a percepção da habilidade dos jogadores e o tempo na equipe.

Para mensurar a rede de confiança foi utilizado procedimento baseado em Kupiers (2009), que construiu a rede de confiança de cinco organizações, por meio de um questionário sociométrico, em que cada respondente poderia listar até cinco nomes de pessoas nas quais confiavam e pelas quais estavam dispostos a arriscar-se sem medo de consequências negativas. No presente estudo, porém, a fim de coletar os dados completos das redes, cada participante respondeu a questão da confiança referente a cada atleta da equipe, colocando como resposta "sim" ou "não" ao lado do nome de cada um (CHOU et al., 2006).

O comprometimento organizacional foi mensurado por meio de um questionário multidimensional proposto e validado por Jackson, Gucciardi e Dimmock (2014) e adaptado de Meyer, Allen e Smith (1993), em que os autores verificaram o comprometimento organizacional de jovens atletas com suas equipes (ver Anexo I). O estudo foi feito com 286 atletas, de 31 times, das seguintes modalidades: futebol, hóquei sobre grama, rúgbi e voleibol. Tendo em vista 
que o presente artigo pretendeu verificar exatamente o comprometimento organizacional dos atletas com suas equipes e que o estudo de Jackson et al. (2014) também foi realizado com jovens em esportes coletivos, revelou-se totalmente adequado adaptar seu questionário.

Para mensurar a habilidade técnica dos atletas, utilizou-se o mesmo método que Lusher, Kremer e Robins (2013) aplicaram com equipes de futebol australiano. Nesta pesquisa, perguntou-se a cada jogador da equipe "quem são os melhores jogadores de seu clube?", e cada jogador poderia nomear quantos jogadores quisesse, exceto a si próprio. Dessa forma, cada jogador obteve um score entre 0 (nenhuma nomeação) e n-1 (nomeado por todos, menos por si próprio). Quanto maior o resultado obtido, maior a qualidade técnica do jogador. Para que tivessem valores passíveis de comparação entre as três equipes, os scores foram ajustados para valores entre 0 e 1 , dividindo-se o score obtido por n-1. Por fim, o tempo de participação na equipe baseou-se na data de ingresso do atleta no COTP e foi medido em meses.

\begin{tabular}{|c|c|c|}
\hline \multicolumn{2}{|c|}{ Quadro 1 - Indicadores dos dados da pesquisa } \\
\hline $\begin{array}{c}\text { Característica dos } \\
\text { respondentes }\end{array}$ & Indicadores & Fundamentação teórica \\
\hline Perfil dos respondentes & $\begin{array}{c}\text { Gênero, idade, local de } \\
\text { residência }\end{array}$ & Klein, Lim, Saltz e Mayer (2004) \\
\hline Confiança & Centralidade de entrada & Sarker, Ahuja, Sarker e Kirkeby (2011) \\
\hline $\begin{array}{c}\text { Comprometimento } \\
\text { organizacional }\end{array}$ & Comprometimento afetivo & $\begin{array}{c}\text { Mayer, Allen e Smith (1993); Jackson, } \\
\text { Gucciardi e Dimmock (2014) }\end{array}$ \\
\hline Qualidade técnica & Qualidade dos atletas & Lusher, Kremer e Robins (2013) \\
\hline Tempo na equipe & Quantidade de meses & Elaborado pelos autores (2016) \\
\hline
\end{tabular}

Fonte: elaborada pelos autores (2016).

Posteriormente foram aplicadas as entrevistas semiestruturadas (ver Anexo II), feitas pessoalmente pelo pesquisador, com os treinadores de cada uma das equipes, utilizando um roteiro elaborado com base na revisão de literatura utilizada neste trabalho. $\mathrm{O}$ intuito foi obter mais informações acerca das equipes pesquisadas, sobretudo em relação aos aspectos que foram objetos deste estudo: confiança, comprometimento, tempo na equipe e qualidade técnica.

\subsection{Procedimentos de análise de dados}

Com base nas respostas aos questionários sociométricos, foi construída, para cada equipe, uma matriz das relações de confiança entre os atletas. Tais matrizes eram 
quadradas, com o mesmo número de linhas e de colunas, de acordo com o número de atletas da equipe em questão e tinham em seus dois eixos os nomes de cada um dos atores da rede. Em seguida foram introduzidas nas matrizes as relações de confiança de cada um dos atletas, onde o valor " 1 " indicava a existência de relação de confiança e o valor "0" indicava sua inexistência. As matrizes foram analisadas com o auxílio do software UCINET, por meio do qual foram obtidas: as redes de confiança de cada uma das equipes, a centralidade de entrada dos atores da rede, a densidade das redes e a relação de atores no centro e na periferia das redes.

Com os dados obtidos, foi feita a análise de cada uma das equipes pesquisadas: futebol feminino e voleibol masculino. Primeiramente, realizou-se uma comparação entre os três atletas com maior e os três com menor centralidade na rede, a fim de verificar se o comprometimento organizacional, o tempo na equipe e a qualidade técnica foram de fato maiores para aqueles atletas com maior centralidade. Para isso, compararam-se as médias dos três aspectos entre o grupo de atletas com maior centralidade e aquele com menor centralidade. $\mathrm{O}$ mesmo procedimento foi realizado para comparar o grupo de atletas no centro da rede e aqueles na periferia.

Também foram feitas análises distintas para cada uma das variáveis independentes pesquisadas: tempo na equipe, comprometimento e qualidade técnica. Para isso, compararam-se os atletas de maior destaque, positivo e negativo, no tocante a cada um dos aspectos. Os jogadores que estivessem acima ou abaixo do desvio-padrão da média da equipe foram destacados, e foi verificada a centralidade de entrada desses atores na rede de confiança, bem como se eles faziam parte do centro ou da periferia da rede.

As entrevistas semiestruturadas foram transcritas, e foram nelas verificados os trechos relacionados aos objetos de estudo da pesquisa, de forma a estabelecer uma relação entre os resultados dos questionários e as respostas dos treinadores.

\section{RESULTADOS DA PESQUISA}

$\mathrm{Na}$ descrição dos resultados, os nomes de todos os atletas foram substituídos por códigos a fim de preservar a identidade e anonimato dos mesmos.

\section{Equipe A - Futebol feminino}


A equipe de futebol feminino tem 18 atletas, com média de idade de 16,22 anos (desvio-padrão $[\mathrm{DP}]=0,71)$. A rede da equipe apresentou uma densidade de 0,405 , com um total de 124 laços estabelecidos entre as jogadoras. A média da centralidade de entrada foi de 6,889 (DP = 2,601). Na análise do centro e periferia da rede, foi verificado que as atletas F2, F3, F4, F6, F7, F9, F12 e F16 figuram no centro, ao passo que as atletas F1, F5, F8, F10, F11, F13, F14, F15, F17 e F18 estão na periferia. $\mathrm{O}$ tempo médio das atletas no Centro Olímpico foi de 38,72 meses $(\mathrm{DP}=15,55), \mathrm{o}$ comprometimento afetivo foi, em média, de 5,078 (DP = 1,116), e a avaliação da qualidade das jogadoras foi, em média, de 0,339 (DP $=0,299$ ).

\section{Equipe B - Voleibol masculino}

O time de voleibol masculino infantil do Centro Olímpico tem 19 atletas, com média de idade de 15,57 $(\mathrm{DP}=0,49)$. A densidade da rede de confiança da equipe foi de 0,480 , com 164 laços de confiança estabelecidos entre os atletas, próximo da metade do total de laços possíveis, e a centralidade de entrada média foi de 8,632. Os jogadores V1, V5, V7, V10, V11, V12, V13, V15 e V16 compõem o centro da rede, ao passo que os atletas V2, V3, V4, V6, V8, V9, V14, V17, V18 e V19 estão na periferia. O tempo médio na equipe foi de 21,42 meses ( $\mathrm{DP}=9,13$ ), o comprometimento afetivo teve uma média de 5,589 (DP =0,869), e a avaliação da qualidade dos jogadores foi de $0,315(\mathrm{DP}=0,287)$.

\subsection{Discussão dos resultados}

\section{Equipe A - futebol feminino}

Ao comparar as três atletas mais centrais (F2, F4 e F7) e as três menos centrais (F11, F15 e F17) da rede de confiança da equipe de futebol feminino, é possível observar que o tempo na equipe, o comprometimento afetivo e a qualidade das jogadoras são bem diferentes, com os três atributos tendo resultados superiores para as atletas com maior centralidade, corroborando o que foi proposto no presente estudo, de que atores com maior comprometimento organizacional, maior qualidade técnica e mais tempo na equipe ocupariam posições mais centrais nas redes de confiança.

A média de tempo na equipe das três atletas mais centrais é de 47,6 meses, contra 35 meses das três menos 
centrais. $\mathrm{O}$ comprometimento afetivo médio das atletas com maior centralidade é bem acima da média do time, de 6,26. Já o das atletas menos centrais foi abaixo da média do grupo e bem menor que o das mais centrais,

Tabela 1 - Médias de tempo no COTP, comprometimento afetivo e qualidade técnica das três atletas com maior centralidade e três atletas com menor centralidade da rede de confiança do time de futebol feminino do COTP.

\begin{tabular}{l|c|c|c}
\hline & $\begin{array}{l}\text { Tempo no COTP } \\
\text { (meses) }\end{array}$ & $\begin{array}{l}\text { Comprometimento } \\
\text { afetivo }\end{array}$ & Qualidade \\
\hline $\begin{array}{l}\text { Atletas com maior } \\
\text { centralidade }\end{array}$ & 47,6 & 6,26 & 0,333 \\
$\begin{array}{l}\text { Atletas com menor } \\
\text { centralidade }\end{array}$ & 35 & 4,46 & 0,078 \\
\begin{tabular}{l} 
Diferença \\
\hline
\end{tabular} & 12,6 & 1,8 & 0,255 \\
\hline
\end{tabular}

Fonte: elaborada pelos autores (2016).

$\mathrm{Na}$ entrevista com o treinador da equipe, ele as atletas F1, F3, F10 e F12 como aquelas que ele entende que possuírem maior confiança dentro do grupo. Nenhuma delas foi uma das três com os maiores valores de centralidade de entrada na rede de confiança, porém todas obtiveram scores acima da média geral da equipe, com as atletas F1, F3 e F10 apresentando centralidade de 7, 8 e 7 , respectivamente, exceto a atleta F12, com centralidade de 5, o que sugere ser a centralidade de entrada na rede de confiança um bom indicador de confiança dentro da equipe.

O técnico também colocou que diversos fatores são levados em conta na escolha da capitã do time, como a relação dela com as demais jogadoras e com a comissão técnica, o tempo no clube e aspectos técnicos e táticos.

Também se compararam as médias das jogadoras do centro com as da periferia, observando-se valores mais altos de tempo na equipe, comprometimento e qualidade para as jogadoras do centro em relação às da periferia. A média de tempo na equipe das atletas do centro foi de 45,7 meses, contra 33,1 daquelas da periferia. O comprometimento afetivo médio das jogadoras do centro foi de 5,875, superior à média das atletas da periferia, de 4,440. Já a média da qualidade das atletas do centro foi de 0,499, ao passo que a média das jogadoras da periferia 
foi de 0,211. Esses resultados também estão de acordo com o proposto na presente pesquisa, indicando uma relação positiva entre a confiança e o tempo na equipe, comprometimento organizacional e qualidade técnica dos atletas.

Tabela 2 - Médias de tempo no COTP, comprometimento afetivo e qualidade técnica das atletas do centro e das atletas da periferia da rede de confiança do time de futebol feminino do COTP.

\begin{tabular}{l|l|l|l}
\hline & $\begin{array}{c}\text { Tempo no COTP } \\
\text { (meses) }\end{array}$ & $\begin{array}{c}\text { Comprometimento } \\
\text { afetivo }\end{array}$ & Qualidade \\
\hline Atletas do centro & 45,7 & 5,875 & 0,499 \\
Atletas da periferia & 33,1 & 4,440 & 0,211 \\
Diferença & 12,6 & 1,435 & 0,288 \\
\hline
\end{tabular}

Fonte: elaborada pelos autores (2016).

A Figura 1 destaca as jogadoras com tempo na equipe acima e abaixo do desvio-padrão da média geral da equipe, permitindo observar que as jogadoras com tempo na equipe acima do desviopadrão ocupam posições mais centrais na rede de confiança, com destaque para a atleta F7, que está há 54 meses na equipe do Centro Olímpico.

A centralidade de entrada média das jogadoras acima do desvio-padrão é de 7,5 , superior à centralidade de entrada média das atletas abaixo do desvio-padrão, que é de 6,5. Além disso, três das quatro atletas acima do desvio-padrão fazem parte do centro da rede, enquanto as duas abaixo do desvio-padrão estão na periferia. 
Figura 1 - Rede de confiança do time de futebol feminino do COTP com atletas com tempo na equipe acima e abaixo do desvio-padrão da média da equipe.

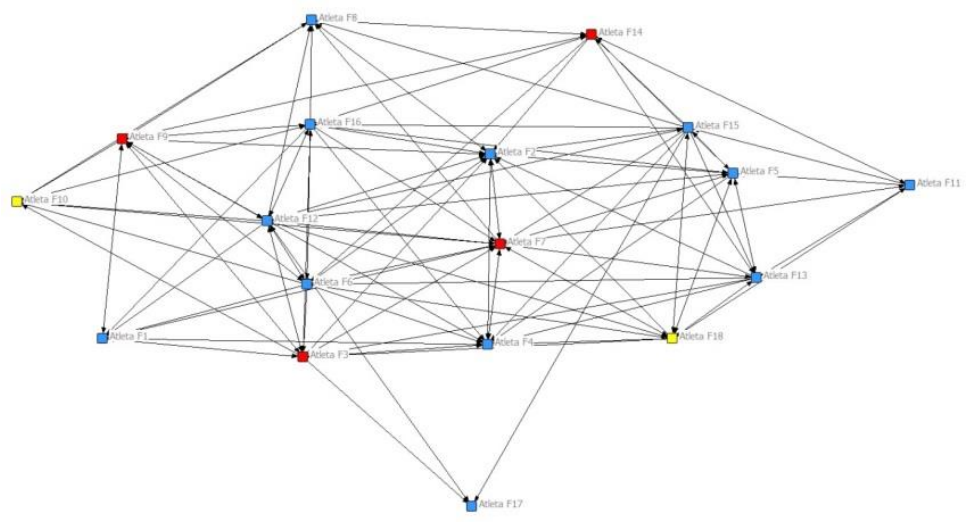

Atletas com tempo na equipe abaixo do desvio-padrão

Atletas com tempo na equipe acima do desvio-padrão

Atletas com tempo na equipe dentro do desvio-padrão

Fonte: elaborada pelos autores (2016).

Esses resultados indicam uma relação positiva entre o tempo na equipe e a confiança, com o que concorda o treinador da equipe, para quem atletas com mais tempo no clube acabam tendo maior confiança das demais jogadoras. Em seu entendimento, isso ocorre porque atletas com mais tempo de casa conhecem melhor como a filosofia e a estrutura da equipe, obtendo assim mais respeito das demais. Inclusive ele ressaltou que procura ter atletas que estão há mais tempo no COTP dentro da equipe, sendo esse um dos fatores levados em conta na formação do grupo. A propósito, a equipe em questão é formada, em sua maioria, por atletas com mais de dois anos de clube.
Ao observar a Figura 2 é possível perceber que as atletas da rede de confiança do futebol feminino com comprometimento organizacional afetivo acima do desvio-padrão da média geral do time ocupam posições mais centralizadas do que aquelas com valores de comprometimento abaixo do desvio-padrão, com destaque para as atletas F2, F12 e F16, que estão em posições próximas e centralizadas dentro da rede.

A centralidade de entrada média das atletas que estão acima do desviopadrão é de 9, enquanto a das jogadoras abaixo do desvio-padrão é de 7. Além disso, as quatro atletas acima do desviopadrão fazem parte do centro da rede, 
enquanto três das quatro atletas abaixo

do desvio-padrão estão na periferia.

Figura 2 - Rede de confiança do time de futebol feminino do COTP com atletas com comprometimento organizacional acima e abaixo do desvio-padrão da média da equipe.

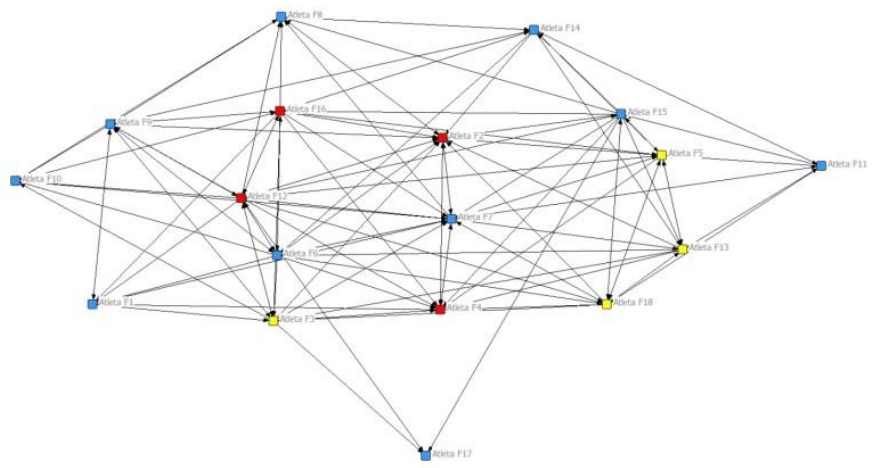

$\square$ Atletas com comprometimento afetivo abaixo do desvio-padrão

Atletas com comprometimento afetivo acima do desvio-padrão

Atletas com comprometimento afetivo dentro do desvio-padrão

Fonte: elaborada pelos autores (2016).

A entrevista do técnico da equipe também foi ao encontro do observado nas redes: em sua opinião, as jogadoras mais comprometidas com a equipe têm de fato uma confiança maior das demais atletas, e isso se reflete inclusive dentro de campo, onde aquelas se sentem mais seguras para realizar ações de risco durante a partida, como tentativas de drible e chutes ao gol.

Ele acrescentou que procura estimular o comprometimento das jogadoras, colocando-as em situações de treinos e jogos em que se valoriza mais o clube e a equipe do que os aspectos individuais. A própria filosofia adotada nos treinamentos, atrelada mais ao aspecto coletivo do jogo do que ao individual, tem como um dos objetivos estimular o comprometimento das atletas.

A Figura 3 apresenta as atletas com scores de qualidade técnica acima e abaixo do desvio-padrão da média da equipe, onde se verificam as jogadoras com maior qualidade em posições mais centralizadas. As atletas F1, F3, F6, F10 e F12 encontram-se em posições muito próximas, formando um núcleo.

A centralidade de entrada média dessas jogadoras é de 6,8, acima da centralidade média das atletas abaixo do desvio-padrão, que é de 4,5. Em relação ao centro e à periferia, três das cinco atletas acima do desvio-padrão estão no centro da rede de confiança, enquanto 
as duas abaixo do desvio-padrão estão

na periferia.

Figura 3 - Rede de confiança do time de futebol feminino do COTP com atletas com qualidade técnica acima e abaixo do desvio-padrão da média geral da equipe.

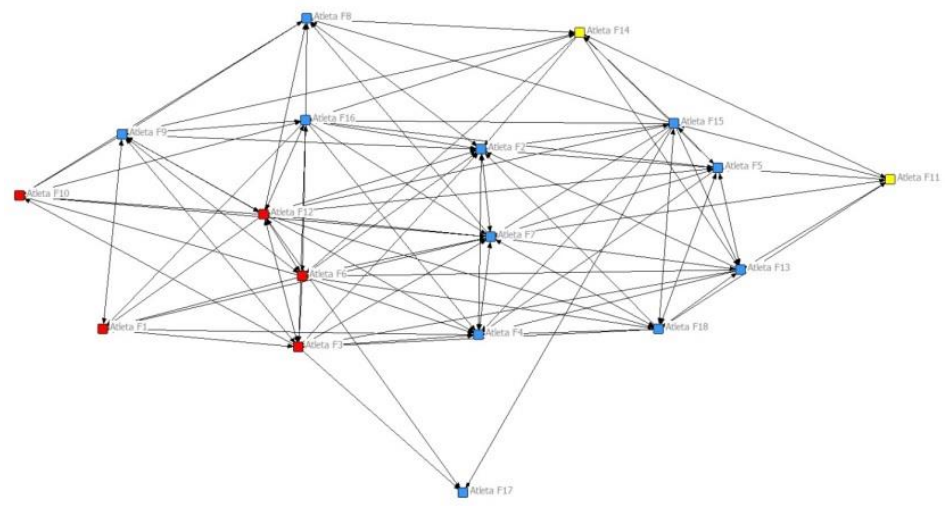

Atletas com qualidade abaixo do desvio-padrão

Atletas com qualidade acima do desvio-padrão

Atletas com qualidade dentro do desvio-padrão

Fonte: elaborada pelos autores (2016).

O treinador do time observou que a qualidade técnica não é fator primordial para que determinada atleta tenha a confiança das demais dentro do grupo. Em seu entendimento, isso está mais ligado à parte psicológica e aos relacionamentos entre as jogadoras do que especificamente ao desempenho esportivo.

\section{Equipe B - voleibol masculino}

Semelhante à equipe de futebol feminino, na comparação dos três atletas mais centrais (V1, V5 e V12) com os três menos centrais (V6, V9 e V14), percebe-se uma diferença significativa no tempo na equipe, no comprometimento afetivo e na qualidade. Em todos esses aspectos, os atletas com maior centralidade obtiveram médias maiores, resultado que corrobora o proposto neste trabalho.

O tempo na equipe foi, em média, de 26,6 meses para os três atletas mais centrais, acima da média geral da equipe, contra 13,6 dos três com menor centralidade, bem abaixo da média do time. O comprometimento afetivo dos atletas mais centrais foi, em média, de 5,46, próximo ao da média geral da equipe, enquanto o dos menos centrais foi, em média, de 4,13, um valor consideravelmente abaixo dos demais. A qualidade dos jogadores mais centrais, por sua vez, teve uma média de 
0,518 , bem acima daquela da equipe,

contra 0,183 dos atletas menos centrais,

também abaixo da média da equipe.

Tabela 3 - Médias de Tempo no COTP, Comprometimento Afetivo e Qualidade Técnica dos Três Atletas com Maior Centralidade e Três Atletas com Menor Centralidade da Rede de Confiança do Time de Voleibol Masculino do COTP.

\begin{tabular}{l|l|l|l}
\hline & $\begin{array}{c}\text { Tempo no COTP } \\
\text { (meses) }\end{array}$ & $\begin{array}{c}\text { Comprometimento } \\
\text { afetivo }\end{array}$ & Qualidade \\
\hline $\begin{array}{l}\text { Atletas com maior } \\
\text { centralidade }\end{array}$ & 26,6 & 5,46 & 0,518 \\
$\begin{array}{l}\text { Atletas com menor } \\
\text { centralidade }\end{array}$ & 13,6 & 4,13 & 0,183 \\
Diferença & 13 & 1,33 & 0,335 \\
\hline
\end{tabular}

Fonte: elaborada pelos autores (2016).

$\mathrm{Na}$ entrevista com o treinador da equipe de voleibol masculino, ele destacou o atleta V13 como aquele que ele entende gozar de mais confiança dos demais dentro da equipe, por ser $\mathrm{o}$ capitão do time e um líder dentro de quadra. Apesar de tal jogador não ser um dos três com maior centralidade de entrada, ele também obteve um score alto nesse quesito, sendo nomeado por 12 dos demais 18 jogadores da equipe. $\mathrm{O}$ atleta indicado pelo treinador é ainda o que apresenta maior valor de comprometimento organizacional na equipe, além de ter obtido o score mais alto de qualidade técnica.
Na comparação entre os jogadores do centro com os da periferia, também são verificados valores mais altos para os atletas do centro nos três aspectos abordados: tempo na equipe, comprometimento e qualidade técnica. $\mathrm{O}$ tempo na equipe dos jogadores do centro foi de 24,8 meses, enquanto o dos atletas periféricos foi de 18,3. O comprometimento afetivo foi um pouco maior para os atletas do centro, de 5,75, contra 5,44 dos atores da periferia. Quanto à qualidade dos jogadores do centro, foi bem superior à daqueles da periferia, de 0,499 contra 0,149. 
Tabela 4 - Médias de tempo no COTP, comprometimento afetivo e qualidade técnica dos atletas do centro e dos atletas da periferia da rede de confiança do time de voleibol masculino do COTP.

\begin{tabular}{l|l|l|l}
\hline & $\begin{array}{c}\text { Tempo no COTP } \\
\text { (meses) }\end{array}$ & $\begin{array}{c}\text { Comprometimento } \\
\text { afetivo }\end{array}$ & Qualidade \\
\hline Atletas do centro & 24,8 & 5,75 & 0,499 \\
Atletas da periferia & 18,3 & 5,44 & 0,149 \\
Diferença & 6,5 & 0,31 & 0,350 \\
\hline
\end{tabular}

Fonte: elaborada pelos autores (2016).

Passando para a Figura 4, observa-se que os atletas que estão no Centro Olímpico há mais tempo ocupam posições mais centrais dentro da rede de confiança da equipe de voleibol masculino, enquanto aqueles com menos tempo na equipe ocupam posições menos centralizadas, à exceção do atleta V1, que, apesar de estar a apenas 10 meses na equipe, já tem uma centralidade de entrada alta, tendo sido nomeado por 16 dos 18 demais jogadores da equipe.

Figura 4 - Rede de confiança do time de voleibol masculino do COTP com atletas com tempo na equipe acima e abaixo do desvio-padrão da média da equipe.

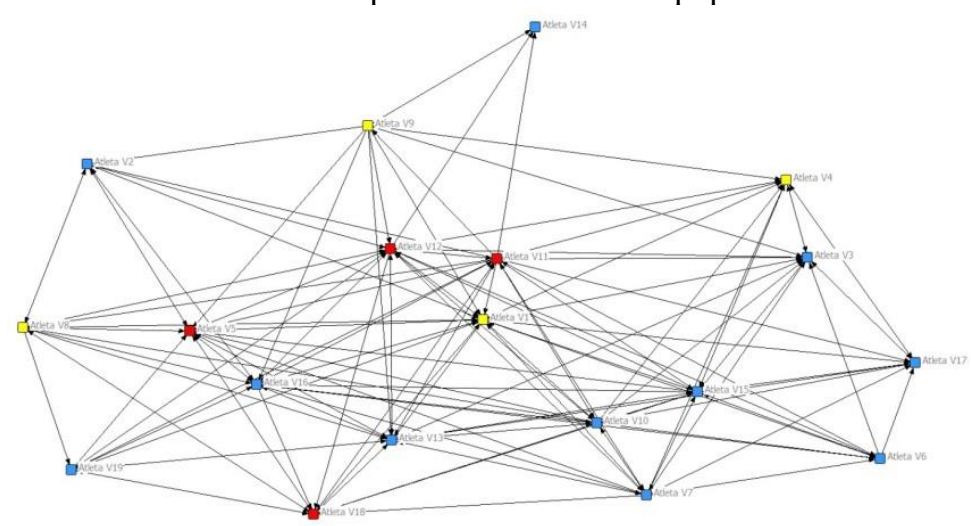

A centralidade de entrada média dos jogadores com tempo no clube acima do desvio-padrão da média foi de 11, contra 8,5 dos atletas abaixo do desvio-padrão. Observa-se ainda que, dos quatro atletas acima do desviopadrão, três estão no centro da rede, enquanto, dos quatro jogadores abaixo do desvio-padrão, três estão na periferia. 
$\square$ Atletas com tempo na equipe abaixo do desvio-padrão

Atletas com tempo na equipe acima do desvio-padrão

Atletas com tempo na equipe dentro do desvio-padrão

Fonte: elaborada pelos autores (2016).

O treinador da equipe também ressaltou a importância de atletas que estão há mais tempo no clube no fator da confiança dentro da equipe, por entender que jogadores com mais tempo de casa conhecem melhor as dinâmicas dos treinamentos e tem a vantagem de entenderem melhor o funcionamento do grupo. Porém, ele pontuou que isso depende bastante da personalidade de cada atleta e que um jogador novo pode acabar ganhando rapidamente a confiança dos demais devido a outros fatores, como seu desempenho e comprometimento nos treinamentos.

O treinador apontou ainda como primordial ter atletas que já estejam há certo tempo na equipe, para se ter uma sequência no processo de formação dos atletas. Contudo, segundo ele, também é importante ter atletas que tenham condições de permanecer na equipe e demonstrem compromisso, pois um eventual atleta desinteressado pode acabar prejudicando o restante da equipe.
Na Figura 5, observa-se que os atletas V16 e V13, com comprometimento afetivo acima do desvio-padrão da média da equipe, ocupam posições centralizadas na rede de confiança, enquanto os atletas V9 e V14, cujos scores de comprometimento afetivo estão abaixo do desvio-padrão, ocupam posições descentralizadas na rede.

A centralidade de entrada média dos jogadores com comprometimento acima do desvio-padrão foi de 12 , enquanto a daqueles abaixo do desviopadrão foi de 2,6, uma diferença bastante alta. Além disso, os dois atletas acima do desvio-padrão estão no centro da rede de confiança, enquanto os três abaixo do desvio-padrão fazem parte da periferia da rede. Tais resultados indicam a existência de uma relação positiva entre o comprometimento organizacional e a confiança. 
Figura 5 - Rede de confiança do time de voleibol masculino do COTP com atletas com comprometimento organizacional acima e abaixo do desvio-padrão da média da equipe.

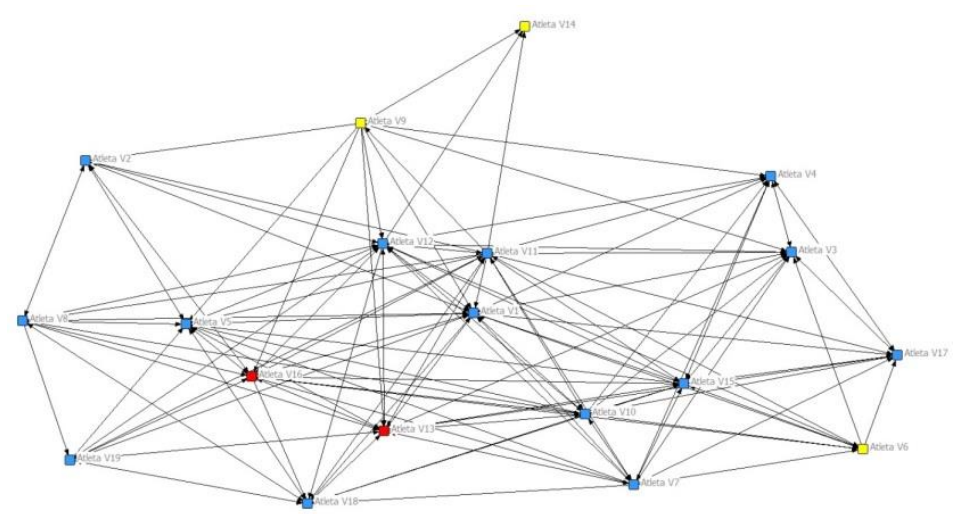

Atletas com comprometimento afetivo abaixo do desvio-padrão

Atletas com comprometimento afetivo acima do desvio-padrão

Atletas com comprometimento afetivo dentro do desvio-padrão Fonte: elaborada pelos autores (2016).

$\mathrm{O}$ treinador da equipe corroborou os resultados, ressaltando a importância do comprometimento dos atletas nas trocas de confiança dentro da equipe, e relatou que procura estimular isso durante os treinamentos, realizando exercícios que gerem interdependência entre os atletas.

Por fim, na Figura 6, é possível observar que os atletas com qualidade acima do desvio-padrão da média da equipe, com centralidade de entrada média de 10,5, estão em posições mais centrais na rede do que os jogadores com qualidade abaixo do desvio-padrão, que obtiveram centralidade de entrada média de apenas 3. Também se percebe que, dos quatro atletas com qualidade acima do desvio-padrão, três ocupam o centro da rede, enquanto os três jogadores com qualidade abaixo do desvio-padrão estão na periferia. 
Figura 6 - Rede de confiança do time de voleibol masculino do COTP com atletas com qualidade técnica acima e abaixo do desvio-padrão da média da equipe.

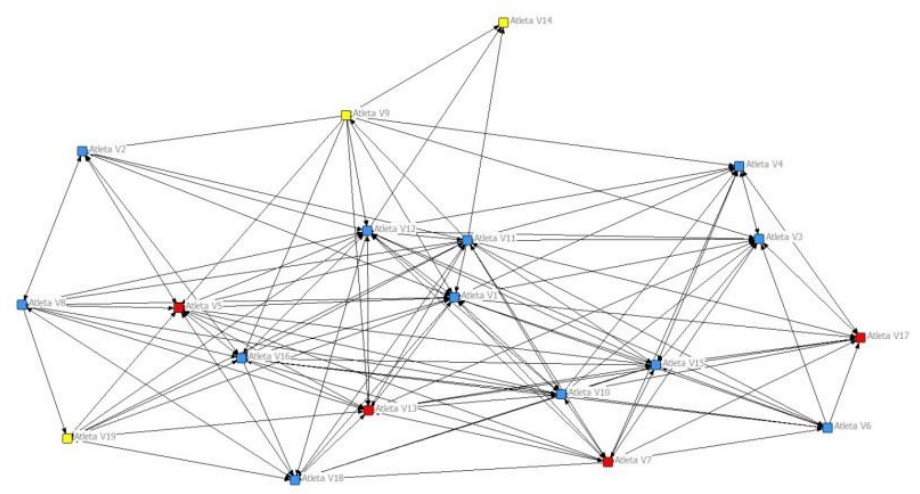

Atletas com qualidade abaixo do desvio-padrão Atletas com qualidade acima do desvio-padrão Atletas com qualidade dentro do desvio-padrão Fonte: elaborada pelos autores (2016).

Para o técnico da equipe, atletas com melhor desempenho esportivo, de fato, gozam de mais confiança dos demais jogadores. Para ele, isso ocorre devido a esses atletas demonstrarem mais segurança nas partidas ou mesmo nos treinamentos. Por sua vez, os jogadores menos habilidosos acabam ficando com grande receio de cometer erros e, em consequência disso, perdem a confiança do restante do grupo.

O treinador colocou ainda que procura estimular as relações de confiança entre os jogadores da equipe, utilizando como estratégia tentar ao máximo promover a interação entre os diferentes atletas do grupo, seja em exercícios durante os treinamentos, seja em atividades fora da quadra.

\section{CONSIDERAÇÕES FINAIS E IMPLICAÇÕES PARA A PRÁTICA}

Os resultados obtidos indicam que a questão de pesquisa proposta no presente artigo foi respondida, uma vez que o campo forneceu evidências empíricas da existência de uma relação entre, de um lado, o comprometimento organizacional, o tempo na equipe e a qualidade técnica e, de outro, a centralidade dos atletas nas redes de confiança. Foi verificado que atletas com maiores scores nessas três variáveis tendem a ter posições mais 
centrais dentro da rede, além de fazerem parte do centro da rede, ao passo que jogadores com menores comprometimento, qualidade técnica e tempo de casa tendem a estar na periferia da rede e ter menor centralidade de entrada, resultados alinhados com o que foi levantado no referencial teórico da presente pesquisa.

Dessa forma, as informações levantadas na pesquisa de campo mostraram-se alinhadas com o objetivo do trabalho, de verificar o que leva um ator a ter maior centralidade nas redes de confiança, observando a relação do comprometimento organizacional, da qualidade técnica e do tempo na equipe com a centralidade nas redes de confiança de equipes esportivas.

O fato de os treinadores entrevistados terem apontado, como atletas que gozam de maior confiança em suas equipes, aqueles com centralidade de entrada acima da média mostra que a utilização da centralidade como indicador de confiança dentro de um grupo parece ser válida e, em alguma medida, já é reconhecida na prática. Além disso, todos os treinadores destacaram a importância dos aspectos abordados no estudo no processo de construção da confiança dentro da equipe.
Como contribuição para a prática está a relação que pode ser feita entre as equipes esportivas com equipes $\mathrm{e}$ grupos de trabalho em empresas e organizações. Assim como aponta a literatura acerca das equipes de alta performance, os resultados deste estudo indicam a importância deles também para a área de gestão, onde profissionais mais comprometidos, mais qualificados e com mais tempo dentro da empresa podem gozar de maior confiança dentro do ambiente corporativo, o que levará a um melhor desempenho organizacional. É importante que as organizações utilizem estratégias que estimulem o desenvolvimento do comprometimento organizacional de seus profissionais, inclusive empregando estratégias semelhantes às do esporte, tais como atividades que promovam a interdependência entre os profissionais e os valores coletivos da organização.

Nessa perspectiva, a questão da qualidade técnica dos atletas, por exemplo, também tem relevância na área gerencial, na medida em que as organizações precisam de profissionais preparados para exercer suas funções. Essa qualificação abrange inclusive capacitações e treinamentos. Quanto ao tempo na equipe, o fato de ele levar a uma maior centralidade na rede 
demonstra a importância de valorizar profissionais que já estejam há certo tempo na empresa, onde os mesmos tendem a desenvolver com o tempo relações de mais confiança com os demais membros de suas organizações.

O estudo também contribui para a área da gestão de equipes esportivas, tendo em vista que a literatura mostra que o comprometimento organizacional e a confiança estão atrelados ao desempenho esportivo. É importante que os gestores esportivos e treinadores levem em conta esses aspectos na formação de suas equipes e nas próprias atividades e treinamentos, a fim de estimular o comprometimento e a confiança entre os atletas.

Fica clara a importância que atletas tecnicamente mais qualificados têm dentro de uma equipe, ao exercerem um tipo de liderança devido ao seu desempenho esportivo. De fato, essa é uma situação corriqueira no esporte, como por exemplo, quando o melhor jogador do time é eleito o capitão, mesmo sendo jovem e ainda tendo um comportamento instável, como é o caso do jogador de futebol Neymar, que foi por certo tempo o capitão da Seleção Brasileira de Futebol.
A questão do tempo na equipe também é de grande relevância para o esporte, onde é comum, sobretudo no esporte profissional, ocorrerem muitas trocas de jogadores nas equipes. No futebol brasileiro, por exemplo, é muito raro ver uma equipe que se mantenha com um mesmo elenco por bastante tempo, sendo comuns a saída e a contratação de jogadores. $\mathrm{O}$ estudo aposta que manter um grupo de jogadores por certo tempo pode trazer vantagens, ao fortalecer as relações de confiança entre os atletas.

Outra contribuição da pesquisa é do ponto de vista acadêmico, ao desenvolver e aprofundar o tema das redes de confiança, ainda incipiente dentro da literatura das redes sociais. Vale lembrar a necessidade de mais estudos abordando diferentes aspectos e atributos das redes de confiança, para que $o$ conceito siga em desenvolvimento e evolução.

Uma das limitações desta pesquisa é o fato de ela ter sido feita apenas com atletas jovens, com 17 anos ou menos. Apesar de já estarem próximos da idade adulta, trata-se de jogadores ainda inexperientes, com características distintas do desportista profissional. Nesse sentido, seria 
interessante realizar uma pesquisa semelhante com equipes esportivas adultas. Outra limitação foi o fato de a pesquisa ter sido feita com duas equipes do mesmo local, o Centro Olímpico de Treinamento e Pesquisa. Seria interessante abordar equipes de diferentes clubes, locais e contextos.

A principal sugestão para pesquisas futuras é a realização de um estudo quantitativo com o mesmo tema, abordando a relação de comprometimento organizacional, tempo e qualidade técnica com a centralidade nas redes de confiança por meio de testes estatísticos. Para isso, seria necessário um melhor desenvolvimento das premissas utilizadas, bem como um número superior de indivíduos na amostra da pesquisa.

Outra sugestão seria realizar um estudo sobre a relação entre a rede de confiança, o comprometimento organizacional e o desempenho esportivo das equipes. Nesse caso, seria verificada a relação entre os atributos das redes de confiança, o comprometimento organizacional e os resultados obtidos nas competições esportivas, de forma a estabelecer uma relação mais concreta desses aspectos com o desempenho em si.
Também pode ser feita uma pesquisa que se aprofunde nas características dos atletas com maior e menor centralidade de entrada nas redes de confiança. Para tanto, seria necessário um foco maior nestes atletas, por meio de entrevistas com os próprios e também com os colegas, mas com o objetivo de investigar o motivo de os jogadores serem os mais confiáveis do grupo. Tal pesquisa estaria atrelada à liderança que tais atores exercem na rede. Outra possível investigação abordaria as questões de gênero e distinção entre os esportes, onde poderiam se comparar as diferenças entre os resultados de equipes do sexo masculino e feminino ou de diferentes modalidades esportivas.

Por fim, verificou-se que a literatura a respeito da confiança e do comprometimento organizacional apresenta resultados contraditórios sobre a relação entre os construtos, com visões ambíguas sobre se a confiança leva ao comprometimento ou viceversa. No presente estudo, a relação estudada foi do comprometimento organizacional como antecedente da confiança, daí caber um estudo que aborde a relação no sentido contrário, da confiança levando ao comprometimento. 


\section{REFERÊNCIAS}

BALBINO, H. F.; WINTERSTEIN, P. J. A atuação de técnicos de seleções nacionais de modalidades coletivas: elementos indicadores para um estudo sobre excelência no esporte. Conexões, v. 6, n. especial, p. 85-595, jul. 2008.

BORGATTI, S. P. et al. Network analysis in the social sciences. Science, v. 323, n. 5916, p. 892-895, 2009.

BORGATTI, S. P.; EVERETT, M. G. Models of core/periphery structures. Social Networks, v. 21, n. 4, p. 375-395, 2000.

BOZIONELOS, N. Intra-organizational network resources: How they relate to career success and organizational commitment. Personnel Review, v. 37, n. 3, p. 249-263, 2008 .

CASIMIR, G.; LEE, K.; LOON, M. Knowledge sharing: influences of trust, commitment and cost. Journal of Knowledge Management, v. 16, n. 5, p. 740-753, 2012.

CASTKA, Pavel et al. Factors affecting successful implementation of high performance teams. Team Performance Management: An International Journal, v. 7, n. 7/8, p. 123-134, 2001.

CHOU, L. et al. Guanxi networks and members' effectiveness in Chinese work teams: Mediating effects of trust networks. Asian Journal of Social Psychology, v. 9, n. 2, p. 79-95, 2006.

DHAR, R. L. Service quality and the training of employees: The mediating role of organizational commitment. Tourism Management, v. 46, p. 419-430, 2015.

DYER, W. G.; DYER, W. G. Jr.; DYER, J. H. Equipes que fazem a diferença (Team Building): Estratégias comprovadas para desenvolver equipes de alta performance. São Paulo: Saraiva, 2011.

EDELENBOS, J.; KLIJN, E. Trust in complex decision-making networks a theoretical and empirical exploration. Administration \& Society, v. 39, n. 1, p. 25-50, 2007. 
GIL, A. C. Como classificar as pesquisas. Como Elaborar Projetos de Pesquisa, v. 4, p. 44-45, 2002.

GOULD-WILLIAMS, J. The importance of HR practices and workplace trust in achieving superior performance: a study of public-sector organizations. International Journal of Human Resource Management, v. 14, n. 1, p. 28-54, 2003.

GRANOVETTER, M. Economic action and social structure: The problem of embeddedness. American Journal of Sociology, p. 481-510, 1985.

The impact of social structure on economic outcomes. The Journal of Economic Perspectives, v. 19, n. 1, p. 33-50, 2005.

ISETT, K. R. et al. Networks in public administration scholarship: Understanding where we are and where we need to go. Journal of Public Administration Research and Theory, v. 21, n. suppl 1, p. i157-i173, 2011.

JACKSON, B. et al. Toward a multidimensional model of athletes' commitment to coach-athlete relationships and interdependent sport teams: A substantivemethodological synergy. Journal of Sport \& Exercise Psychology, v. 36, n. 1, p. 52 68, 2014.

JOO, B.; PARK, S. Career satisfaction, organizational commitment, and turnover intention: The effects of goal orientation, organizational learning culture and developmental feedback. Leadership \& Organization Development Journal, v. 31, n. 6, p. 482-500, 2010.

KATZENBACH, Jon R.; SMITH, Douglas K. Equipes de alta performance: conceitos, princípios e técnicas para potencializar o desempenho das equipes. Gulf Professional Publishing, 2001.

KIM, K. Y.; EISENBERGER, R.; BAIK, K. Perceived organizational support and affective organizational commitment: Moderating influence of perceived organizational competence. Journal of Organizational Behavior, v. 37, n. 4, p. 558-593, 2016.

KIM, Y. K. et al. A conceptual framework for understanding relationships between sport consumers and sport organizations: A relationship quality approach. Journal of Sport Management, v. 25, n. 1, p. 57-69, 2011. 
KLEIN, K. J. et al. How do they get there? An examination of the antecedents of centrality in team networks. Academy of Management Journal, v. 47, n. 6, p. 952963, 2004.

KRACKHARDT, D.; HANSON, J. R. Informal networks. Harvard Business Review, v. 71, n. 4, p. 104-111, 1993.

LARSEN-FREEMAN, D. On the complementarity of chaos/complexity theory and dynamic systems theory in understanding the second language acquisition process. Bilingualism: Language and Cognition, v. 10, n. 01, p. 35-37, 2007.

LECY, J. D.; MERGEL, I. A.; SCHMITZ, H. P. Networks in public administration: current scholarship in review. Public Management Review, v. 16, n. 5, p. 643-665, 2014.

LI, L. The effects of trust and shared vision on inward knowledge transfer in subsidiaries' intra-and inter-organizational relationships. International Business Review, v. 14, n. 1, p. 77-95, 2005.

LUSHER, D.; ROBINS, G.; KREMER, P. The application of social network analysis to team sports. Measurement in Physical Education and Exercise Science, v. 14, n. 4, p. 211-224, 2010.

LUSHER, D.; KREMER, P.; ROBINS, G. Cooperative and competitive structures of trust relations in teams. Small Group Research, v. 45, n. 1, p. 3-36, 2013.

MACAMBIRA, M. O.; BASTOS, A. V. B. Comprometimento organizacional e redes sociais informais: a estrutura das relações interpessoais e o vínculo com a organização. In: PAREDES, A. (org.). Redes Sociales: Análisis e Intervención Psicosociales. Universidad del Aconcagua, 2009. p. 179-202.

MACH, M.; DOLAN, S.; TZAFRIR, S. The differential effect of team members' trust on team performance: The mediation role of team cohesion. Journal of Occupational and Organizational Psychology, v. 83, n. 3, p. 771-794, 2010.

MEYER, J. P.; ALLEN, N. J. A three-component conceptualization of organizational commitment. Human Resource Management Review, v. 1, n. 1, p. 61-89, 1991. 
MEYER, J. P.; ALLEN, N. J.; SMITH, C. A. Commitment to organizations and occupations: Extension and test of a three-component conceptualization. Journal of Applied Psychology, v. 78, n. 4, p. 538, 1993.

OLIVEIRA, A. B. de et al. Estudo da rede de co-autoria e da interdisciplinaridade na produção científica com base nos métodos de análise de redes sociais: avaliação do caso do programa de pós-graduação em ciência da informação-PPGCI/UFMG 10.5007/15182924.2006 v11nesp1p179. Encontros Bibli: Revista Eletrônica de Biblioteconomia e Ciência da Informação, v. 11, n. 1, p. 179-194, 2007.

PREFEITURA DE SÃO PAULO. Centro Olímpico de Treinamento e Pesquisa. Disponível em: <http://www.prefeitura.sp.gov.br/cidade/secretarias/esportes/centro_ olimpico>. Acesso em: 08 nov. 2016.

PRELL, C.; HUBACEK, K.; REED, M. Stakeholder analysis and social network analysis in natural resource management. Society and Natural Resources, v. 22, n. 6, p. 501-518, 2009.

RAMPERSAD, G.; QUESTER, P.; TROSHANI, I. Examining network factors: commitment, trust, coordination and harmony. Journal of Business \& Industrial Marketing, v. 25, n. 7, p. 487-500, 2010.

SARKER, S. et al. The role of communication and trust in global virtual teams: A social network perspective. Journal of Management Information Systems, v. 28, n. 1, p. 273-310, 2011.

SCOTT, J. Social network analysis: developments, advances, and prospects. Social Network Analysis and Mining, v. 1, n. 1, p. 21-26, 2011.

SILVA, R. S. et al. Ações Conjuntas e Trocas de Informações Existentes entre Pequenas Lojas de um Shopping Atacadista de Moda. Revista da Micro e Pequena Empresa, v. 8, n. 2, p. 38-53, 2014.

SODA, G.; ZAHEER, A. A network perspective on organizational architecture: performance effects of the interplay of formal and informal organization. Strategic Management Journal, v. 33, n. 6, p. 751-771, 2012.

SPARROWE, R. T. et al. Social networks and the performance of individuals and groups. Academy of Management Journal, v. 44, n. 2, p. 316-325, 2001. 
UGBORO, I. O. Influence of managerial trust on survivors' perceptions of job insecurity and organizational commitment in a post restructuring and downsizing environment. The Journal of Behavioural and Applied Management, v. 4, n. 3, p. 230-53, 2003.

YAKOVLEVA, M.; REILLY, R. R.; WERKO, R. Why do we trust? Moving beyond individual to dyadic perceptions. Journal of Applied Psychology, v. 95, n. 1, p. 79-91, 2010.

YILMAZ, K. The relationship between organizational trust and organizational commitment in Turkish primary schools. Journal of Applied Sciences, v. 8, n. 12, p. 2293-2299, 2008.

ZAHEER, A.; MCEVILY, B.; PERRONE, V. Does trust matter? Exploring the effects of interorganizational and interpersonal trust on performance. Organization Science, v. 9 , n. 2, p. 141-159, 1998

ZEFFANE, R.; TIPU, S. A.; RYAN, J. C. Communication, commitment \& trust: Exploring the triad. International Journal of Business and Management, v. 6, n. 6, p. 77-87, 2011. 


\section{ANEXO I - Comprometimento organizacional (JACKSON et al., 2014)}

\section{Comprometimento afetivo}

1. Eu ficaria muito feliz em passar o resto da minha vida esportiva com esta equipe.

2. Eu sinto como se os problemas da minha equipe fossem meus próprios problemas.

3. Eu não sinto um forte sentimento de vínculo na minha relação com esta equipe. *

4. Eu não me sinto emocionalmente ligado a esta equipe. *

5. Minha relação com esta equipe tem um grande significado pessoal para mim.

\section{Comprometimento normativo}

6. Eu não sinto qualquer obrigação de permanecer com esta equipe. *

7. Mesmo que fosse bom para mim, eu não sinto que seria correto deixar minha equipe agora.

8. Eu me sentiria culpado se deixasse esta equipe agora.

9. Esta equipe merece a minha lealdade.

10. Eu não deixaria esta equipe agora, porque tenho um sentimento de obrigação com os(as) outros jogadores(as) dela.

11. Eu devo muito a esta equipe.

\section{Comprometimento continuado}

12. Neste momento, permanecer nesta equipe é uma questão tanto de necessidade, quanto de desejo.

13. Eu sinto que tenho muito poucas outras opções a considerar se deixar esta equipe.

14. Se já não tivesse me dedicado tanto a esta equipe, eu poderia considerar jogar em uma diferente.

15. Uma das poucas consequências negativas de deixar esta equipe seria a falta de equipes alternativas disponíveis.

16. Para mim, seria muito difícil deixar esta equipe agora, mesmo se eu quisesse.

17. Muito da minha vida esportiva seria interrompido se eu decidisse deixar esta equipe agora.

* Código reverso 


\section{ANEXO II - Roteiro da entrevista semiestruturada com os treinadores (elaborada pelos autores, 2016).}

1) Quais são os atletas da equipe que gozam de mais confiança dos demais? Você acha que os atletas mais comprometidos com a equipe têm mais confiança dos demais?

2) Em sua opinião, os atletas da equipe que têm melhor desempenho esportivo gozam de mais confiança dos demais? Explique por quê.

Mathieu e Zajac (1990);

Chou, Cheng, Huang e

Cheng (2006)

3) Em sua opinião, os atletas com maior tempo dentro do Centro Olímpico gozam de mais confiança dos demais? Explique por quê.

4) Dentro da equipe, você procura estimular as relações de confiança entre os atletas? Se sim, como isso é feito?

5) Dentro da equipe, você procura estimular o Mathieu e Zajac (1990) comprometimento dos atletas com a equipe? Se sim, como isso é feito?

6) Você procura ter no grupo atletas que já estejam há Lusher, Kremer e Robins um certo tempo no Centro Olímpico ou isso não é (2013) levado em conta?

7) Quais fatores você leva mais em conta na definição Day, Sin e Chen (2004) do capitão da equipe? 